\title{
Sex differences in parent and child pain ratings during an experimental child pain task
}

\author{
Erin C Moon $\mathrm{BA}^{1,2}$, Christine T Chambers $\mathrm{PhD}^{2,3}$, Anne-Claire Larochette $\mathrm{BA}^{4}$, Kelly Hayton $\mathrm{BSc}^{2}$, \\ Kenneth D Craig $\mathrm{PhD}^{5}$, Patrick J McGrath $\mathrm{PhD}^{2,6}$
}

\begin{abstract}
EC Moon, CT Chambers, A-C Larochette, K Hayton, KD Craig, PJ McGrath. Sex differences in parent and child pain ratings during an experimental child pain task. Pain Res Manage 2008;13(3):225-230.
\end{abstract}

Research in the field of pediatric pain has largely ignored the role of fathers in their children's pain experiences. The first objective of the present study was to examine the effect of the presence of mothers versus fathers on children's subjective ratings, facial expressions and physiological responses to acute pain. The second objective was to examine whether child and parent sex influence parents' proxy ratings of their children's pain. The final objective was to compare levels of agreement between mothers' and fathers' assessments of their children's pain. Participants included 73 children ( 37 boys, 36 girls), four to 12 years of age, along with 32 fathers and 41 mothers. Children undertook the cold pressor pain task while observed by one of their parents. During the task, the children's heart rates and facial expressions were recorded. Children provided self-reports and parents provided proxy reports of child pain intensity using the seven-point Faces Pain Scale. Neither child nor parent sex had a significant impact on children's subjective reports, facial expressions or heart rates in response to acute pain. Fathers gave their sons higher pain ratings than their daughters, whereas mothers' ratings of their sons' and daughters' pain did not differ. Kappa statistics and $t$ tests revealed that fathers tended to be more accurate judges of their children's pain than mothers. Overall, this research highlights the importance of examining both parent and child sex differences in pediatric pain research.

Key Words: Agreement; Assessment; Child; Cold pressor; Pain; Parent

Dain is a very common experience in childhood. Epidemiological studies indicate that up to one-quarter of children experience chronic pain (recurrent or continuous pain for longer than three months) (1). Acute painful experiences are also frequent over the course of a child's development, from routine immunizations to everyday bumps and scrapes. When these painful experiences are not serious, parents usually take on the role of assessing their child's pain and providing comfort and treatment. When a child is seriously hurt and must be assessed and treated by professionals, parents are typically present and are frequently called on to provide information regarding their child's pain (2).

Research conducted in both clinical and laboratory settings has demonstrated that children's pain experiences are significantly impacted by their parents' behaviour (eg, 3-7). These findings are consistent with social ecological models of pain that demonstrate the importance of social context as a proximal and

\section{Les différences selon le sexe de l'évaluation de la douleur par le parent et l'enfant pendant une tâche douloureuse expérimentale effectuée par l'enfant}

Les recherches dans le domaine de la douleur pédiatrique ont largement fait abstraction du rôle des pères dans les expériences de douleur de leurs enfants. Le premier objectif de la présente étude consistait à examiner l'effet de la présence des mères par rapport aux pères sur les évaluations subjectives, les expressions faciales et les réponses physiologiques des enfants à la douleur aiguë. Le deuxième objectif consistait à examiner si le sexe de l'enfant et du parent influe sur les évaluations indirectes de la douleur de leurs enfants par les parents. Le dernier objectif consistait à comparer les taux de concordance entre les évaluations de la douleur de leurs enfants par les pères et les mères. Les participants se composaient de 73 enfants ( 37 garçons, 36 filles) de quatre à 12 ans, de 32 pères et de 41 mères. Les enfants ont entrepris une tâche douloureuse de pression à froid sous l'observation de l'un de leurs parents. Pendant la tâche, les auteurs ont enregistré la fréquence cardiaque et les expressions faciales des enfants. Les enfants ont remis des autoévaluations et les parents, des rapports indirects de l'intensité de la douleur ressentie par l'enfant au moyen de l'échelle de douleur faciale en sept points. Ni le sexe de l'enfant, ni celui des parents n'avait de répercussion significative sur les déclarations subjectives des enfants, leur expression faciale ou leur fréquence cardiaque en réponse à une douleur aiguë. Les pères évaluaient la douleur de leur garçon à un taux plus élevé que celle de leur fille, tandis que les mères n'évaluaient pas différemment la douleur de leur garçon ou de leur fille. L'analyse statistique Kappa et les tests t on révélé que les pères jugent avec plus d'exactitude la douleur de leurs enfants que les mères. Dans l'ensemble, cette recherche fait ressortir l'importance d'examiner les différences des deux parents et de l'enfant selon le sexe dans le cadre des recherches sur la douleur pédiatrique.

distal determinant of pain and pain management (8). The focus of the present study is on the immediate transaction between children and parents present at the time pain is experienced. Remarkably, research in the field of pediatric pain has focused almost exclusively on mothers, overlooking fathers' roles in their children's pain experiences (9). In fact, on close scrutiny, the majority of studies that appear to investigate the role of 'parents' in child pain either exclude fathers or collapse data from a handful of fathers with data gathered from a larger sample of mothers. A recent study (10) exploring fathers' inclusion in pediatric psychology research conducted between 1996 and 2003 reported that only $8.9 \%$ of articles published in pediatric and health journals examined similarities and differences between mothers and fathers.

Explanations for the under-representation of fathers in research include the assumption that it is more difficult to recruit fathers to participate in research with their children, and

${ }^{1}$ Department of Psychology, Dalhousie University; ${ }^{2}$ Centre for Pediatric Pain Research, IWK Health Centre; ${ }^{3}$ Departments of Pediatrics and

Psychology, Dalhousie University and IWK Health Centre; ${ }^{4}$ Department of Psychology, Queen's University; Department of Psychology,

University of British Columbia; ${ }^{6}$ Departments of Pediatrics, Psychiatry and Psychology, Dalhousie University and IWK Health Centre

Correspondence: EC Moon, Centre for Pediatric Pain Research - West, 5850/5980 University Avenue, PO Box 9700, Halifax, Nova Scotia

B3K 6R8. Telephone 902-470-6769, fax 902-470-7118, e-mail Erin.Moon@Dal.ca 
reliance by researchers on traditional theories about parentchild relationships that are based on outdated societal norms (11). Cassano et al (12) argued that because of an increasing number of mothers entering the workforce, fathers are more involved in their children's upbringing. Seagull (13) also addressed the over-reliance on mothers in pediatric research and urged researchers to consider looking beyond mothers, stressing that fathers play an important role in child-rearing and should be involved in research and treatment.

According to social-cognitive learning theory, children develop a sense of their own masculinity and femininity, as well as an understanding of gender-congruent behaviours through modelling, imitation, reinforcement and punishment (14). As outlined by Unruh and Campbell (9), children's pain experiences are socialized by their parents in a manner that is influenced by the sex of both the parent and the child. Sex differences in adult pain experiences are well-established. For example, women have an increased risk for many chronic pain conditions and generally report a lower pain threshold and tolerance than men (15). Findings from pediatric studies examining sex differences in children's pain are less consistent than those reported in adult populations (9). However, girls have been found to give higher reports of pain unpleasantness (16) and pain intensity $(17,18)$ than boys. Girls have also been found to be significantly more likely than boys to express their pain (19).

Studies that examine the effects of both child and parent sex on child pain experiences are rare. In one such study (20), girls reported that they received more parental encouragement of illness behaviour related to stomachaches than boys. In the same study, data collected from both children and parents indicated that mothers encouraged their children's illness behaviour more than fathers. As well, in an early study of immunization pain in five-year-old children, Schechter et al (21) found that fathers were more likely than mothers to believe that boys handled pain better than girls, that comforting a child encouraged the child to cry more and that too much comfort would spoil the child.

Data from both adults and children, as well as anecdotal evidence, suggest that pain expression is more acceptable in women and girls than in men and boys (14). It is likely that a parental socialization process in which the expression of pain in girls is accepted or encouraged by parents and the expression of pain in boys is ignored or even actively discouraged may account for some of the sex differences in pain reporting by children $(14,22)$. Parental modelling also contributes to this socialization process. Given that same-sex parents also serve as role models for their children, gender role variation is also perpetuated across generations. Currently, we do not have a good understanding of mothers' and fathers' unique roles in the socialization process of pain.

The present study was a first descriptive step toward understanding sex differences in parent and child pain ratings during an experimental pain task (the cold pressor task). Various research designs are available to examine parental influences on child pain. It is possible to contrast the impact of mothers alone and fathers alone, or to examine the presence of both on the child. In the present study, a cross-sectional design contrasting the impact of mothers and fathers alone was used. The first purpose of the present study was to examine whether children whose mothers were present had different pain experiences, as measured by self-report, facial expression and physiological reactivity (heart rate), than children whose fathers were present. It was predicted that girls would report higher pain intensity and show greater facial reactivity in response to pain than boys, and that both boys and girls would provide higher pain intensity ratings and show greater facial reactivity when in pain in the presence of mothers than in the presence of fathers. Consistent with previous research on children's physiological responses to cold pressor pain (6), it was also hypothesized that child sex would not have a significant impact on heart rate during the cold pressor task. No specific prediction about the effect of parent sex on heart rate during the cold pressor task was made.

The second purpose of the present study was to examine whether child and parent sex influenced parents' proxy ratings of their children's pain intensity. Following from our prediction that both boys and girls would show greater facial reactivity to pain in the presence of mothers, we hypothesized that mothers would report higher child pain intensity ratings than fathers. The third purpose of the present study was to compare mothers' and fathers' assessments of their children's pain intensity to determine if there were sex differences in parents' level of agreement with their children's reports of pain intensity. A study and review by Chambers et al (2) revealed low levels of agreement between parent and child reports of acute pain, with parents generally underestimating their child's pain intensity levels. However, the majority of parents in the study (2) were mothers - fathers made up less than $4 \%$ of the sample. The present study is the first to draw a comparison between mother-child and father-child agreement in child pain intensity ratings. It was hypothesized that both mothers and fathers would underestimate their children's pain intensity levels. Because it was predicted that children whose fathers were present would display less pain than children whose mothers were present, it was also predicted that fathers would underestimate their children's pain to a greater extent than mothers.

\section{METHODS}

\section{Participants}

Participants included 73 children ( 37 boys, 36 girls), between four and 12 years of age (mean [ \pm SD] age 8.04 \pm 1.94 years), along with one of their parents. Thirty-two fathers and 41 mothers participated with their children. Parents ranged in age from 30 to 61 years (mean age $40.07 \pm 5.67$ years) and $84 \%$ were married. The majority of children were identified by their parents as Caucasian (56 Caucasian, 12 Asian, three IndoCanadian, two African-Canadian). Families were of middle to upper socioeconomic status (Class II, Hollingshead Index [23]). All children were healthy and pain-free, could speak English and did not suffer from any obvious cognitive disability. The present study was approved by the University of British Columbia's Behavioural Research Ethics Board.

The 73 children and their parents included in this sample were a subset of a total sample of 110 children who originally took part in the study. Children were asked to complete an experimental pain task in the presence of one of their parents (a $60 \mathrm{~s}$ cold pressor task, described in detail below). Throughout this task, child and parent pain measures were recorded. However, children were told that they could discontinue the task if it became too uncomfortable or painful for them to continue. Thirty-seven children (19 boys, 18 girls) of the total sample of 110 chose to discontinue the task before $40 \mathrm{~s}$ were complete. These children were excluded from the analyses 
because they were missing data for two of the three cold pressor phases. In addition, because mother and father proxy ratings of pain were of interest, it was decided that children would need to leave their hand in the water for at least $40 \mathrm{~s}$ to provide parents with sufficient information on which to base their pain ratings.

\section{Materials}

Cold pressor: The cold pressor apparatus provided the pain stimulus. It was constructed using a commercially manufactured plastic cooler $23.5 \mathrm{~cm}$ wide, $43.5 \mathrm{~cm}$ long and $28.0 \mathrm{~cm}$ deep, with an $11 \mathrm{~cm} \times 11 \mathrm{~cm}$ square opening at the top. The cooler contained $11^{\circ} \mathrm{C}\left( \pm 1^{\circ} \mathrm{C}\right)$ ice-cooled water and a pump that continuously circulated the water to maintain a constant temperature. The cold pressor has been widely used as a valid and ethically appropriate experimental stimulus for inducing clinically significant levels of pain in children across a number of pediatric studies (24).

Faces Pain Scale (25): The Faces Pain Scale (FPS) was used to measure pain intensity. This scale consists of a series of seven diagrammatic faces graded by the degree of pain expressed, with scores ranging from 0 to 6 . The FPS is widely used to gather self-report pain ratings from children as well as perceived pain reports from parents. It presents users with facial expressions of pain that are not confounded by other emotions and has been demonstrated to be more valid than other similar faces scales (26). Before participation in the study, children were trained to use the FPS by responding to a series of questions demonstrating the difference between physical and emotional pain (eg, pain felt from a bee sting or being called mean names).

Facial expression: The Child Facial Coding System (CFCS) was used to code discrete facial actions shown to indicate pain in previous research (eg, brow lower, eye squeeze, nose wrinkler [27]). There is good evidence for the reliability and validity of the CFCS for coding children's facial responses to pain (28).

Heart rate: The heart rate (beats/min) of each child was measured with a Polar (Polar, USA) heart rate watch and chest band.

\section{Procedure}

Parents and children visiting Science World, a family-oriented museum featuring scientific and educational exhibits in Vancouver, British Columbia, were approached by researchers inviting them to participate in the study. A research assistant obtained parental consent and assent from the child at this time following an explanation of the task to the family. Once consent was obtained, each child and one of his or her parents was brought behind a screen to complete the cold pressor task. The parent was seated opposite his or her child. After a $60 \mathrm{~s}$ baseline waiting period, the child was instructed to submerge his or her hand in a cooler of $11^{\circ} \mathrm{C}$ water for as long as he or she could tolerate, up to $60 \mathrm{~s}$. Children were videotaped throughout the cold pressor task.

All pain measures were collected during three separate $10 \mathrm{~s}$ phases of the cold pressor task. Phase 1 was the first $10 \mathrm{~s}$ of the child's hand submersion, phase 2 was 30 s to 40 s into submersion and phase 3 was the last $10 \mathrm{~s}$ of submersion. For each phase, children and parents were prompted to provide independent pain ratings using the FPS. Children pointed to the face, using the hand not subjected to the cold, with their parents unable to see their ratings. Parents were asked to rate their child's pain by circling the face selected on a paper version of the scale provided. Scores were then averaged across all three phases to produce total FPS scores for both children and parents. Child heart rate scores were also averaged across all three phases.

Because very few children had both a mother and a father present and able to participate (eg, only one parent had accompanied the child to the museum, or the other parent was required to care for other children while the family participated), in no case did both a mother and a father rate the same child's pain. Children received a certificate and pin as compensation for their participation.

Facial coding was completed by a trained coder who had demonstrated sufficient proficiency in coding with CFCS by passing a baseline training test. The threshold for passing this test is an inter-rater reliability of 0.75 , an acceptable level given that various facial actions in CFCS are coded not only for presence versus absence, but also for intensity level. Coding for the present study was completed for the three phases of the cold pressor task. A second trained coder independently coded data from 10 of the 73 participants (14\%) and inter-rater reliability was found to be 0.81 , indicating an acceptable level of reliability.

Data on the 13 CFCS facial actions from phase 3 of the cold pressor task (the most painful phase) were subjected to principal components factor analysis. A two-factor solution that accounted for $47 \%$ of the variance was the best fit for the data. One facial action (blink) did not load strongly on either factor and was dropped. The facial actions that loaded on the first factor (squint, nasolabial furrow, cheek raiser, open lips, upper lip raise, lip corner puller, horizontal mouth stretch) represented general facial expressivity, while the facial actions that loaded on the second factor (brow lower, eye squeeze, flared nostril, nose wrinkler, vertical mouth stretch) were facial actions associated with a 'pain face' in other research (eg, 27). Therefore, it was decided that the second factor ('pain face') would be used in further analyses. For each child, a total facial expression score per phase was created by summing his or her scores on each of the five facial actions included in the second factor.

\section{RESULTS}

Children's mean self-report of pain intensity was $1.84 \pm 1.60$ on the 0 to 6 scale (range 0 to 5.33 ) across the three phases. A twoway between-subjects ANOVA was conducted to examine the effects of child and parent sex on children's average self-reports. There was no significant difference between the pain intensity ratings of boys and girls $(F[1,69]=0.002$, not significant $[\mathrm{ns}])$. In addition, there was no significant difference in pain intensity ratings for children whose mothers were present versus children whose fathers were present $(F[1,69]=3.53$, ns $)$.

Parents' mean proxy rating of child pain intensity was $1.54 \pm 0.88$ (range 0 to 3.67) across the three phases. Mean parent ratings as a function of child and parent sex are displayed in Table 1. A second two-way between-subjects ANOVA was conducted to investigate the effects of child and parent sex on parents' proxy ratings. This analysis revealed a significant main effect of child sex $(\mathrm{F}[1,69]=4.21, \mathrm{P}<0.05)$ on parents' ratings, with parents rating more pain in their sons than in their daughters. However, there was a significant interaction between child sex and parent sex $(\mathrm{F}[1,69]=6.27, \mathrm{P}<0.05)$. Follow-up one-way between-subjects ANOVAs determined that fathers reported higher pain ratings for their sons than their daughters $(\mathrm{F}[1,30]=6.49, \mathrm{P}<0.01)$, whereas mothers' ratings of their sons' and daughters' pain intensity did not differ significantly $(\mathrm{F}[1,39]=0.12$, ns $)$. 
TABLE 1

Overall mean parent proxy rating of child pain intensity as a function of child sex and parent sex

\begin{tabular}{lccc}
\hline & \multicolumn{2}{c}{ Child sex } & \\
\cline { 2 - 3 } Parent sex & Male & Female & Total \\
\hline Male (father) & $2.06 \pm 0.99$ & $1.12 \pm 0.78$ & $1.47 \pm 0.97$ \\
Female (Mother) & $1.55 \pm 0.80$ & $1.65 \pm 0.86$ & $1.59 \pm 0.81$ \\
Total & $1.72 \pm 0.89$ & $1.36 \pm 0.84$ & $1.54 \pm 0.88$ \\
\hline
\end{tabular}

Results presented as mean $\pm S D$

Children's mean facial expression score was $0.40 \pm 0.46$ (range 0 to 2.11 ) and their mean heart rate was $101.58 \pm 11.60$ beats/min (range 78 beats/min to 130.17 beats/min) across the three phases. A set of two-way between-subjects ANOVAs was carried out to examine the effects of child sex and parent sex on child facial expressions and heart rate in response to pain. These tests indicated that neither child sex (facial expression: $F[1,66]=0.42$, ns; heart rate: $F[1,67]=0.01$, ns) nor parent sex (facial expression: $F[1,66]=0.51$, ns; heart rate: $F[1,67]=0.06$, ns) had a significant impact on these variables.

To examine precise levels of parent-child agreement in pain ratings as per recommendations by Chambers et al (2), kappa statistics and paired-samples $t$ tests were conducted separately for each of the three phases of the cold pressor task (Table 2). Kappa statistics provide an index of agreement level where $k<0.40=$ poor agreement, $k$ between 0.40 and 0.75 = good agreement and $k>0.75=$ excellent agreement (29). Due to insufficient statistical power, child sex differences in parent-child agreement were not analyzed; instead, parent sex differences in parent-child agreement were focused on. For phase 1, mother-child agreement could be classified as 'poor' $(k=0.00)$ while father-child agreement came close to a level that could be classified as 'good' $(k=0.36)$. Paired-samples $t$ tests for phase 1 showed no significant differences between mothers' and children's or fathers' and children's ratings. For phases 2 and 3, kappa statistics indicated that mother-child and father-child agreement was poor (for mothers $k=0.00$ and 0.07 , respectively; for fathers $k=-0.02$ and 0.08 , respectively) and paired-samples $t$ tests revealed that while mothers significantly underestimated their children's pain in these phases, there were no significant differences between fathers' and children's pain ratings.

\section{DISCUSSION}

The present study investigated the importance of both parent and child sex differences for children's pain experiences, and parents' proxy ratings of their children's pain. The first purpose of the present study was to examine whether children's pain experiences (as measured by subjective pain intensity ratings, facial expression and heart rate) differed when mothers were present versus when fathers were present. Contrary to our hypotheses, girls in the present study did not, on average, report higher pain intensity than boys. This finding contrasts with previous research in which girls rated their pain intensity as being higher than boys in clinical and experimental pain situations $(17,18)$. However, sex differences in child pain are known to be inconsistent (9). A number of studies $(6,7,30)$ conducted using the cold pressor task with children in the same age range as the present study have also failed to find sex differences in child pain intensity ratings. In another study of sex differences in child pain intensity ratings, Goodenough et al (16) found that while boys and girls provided similar pain
TABLE 2

Agreement between mean parent proxy ratings and child self-reports of pain intensity by phase

\begin{tabular}{lcccccc}
\hline & \multicolumn{2}{c}{ Mothers $(\mathbf{n = 4 1 )}$} & & \multicolumn{2}{c}{ Fathers $(\mathbf{n = 3 2 )}$} \\
\cline { 2 - 3 } \cline { 5 - 6 } Phase & Pain ratings & Kappa & & Pain ratings & Kappa \\
\hline 1 & Mother: $0.85 \pm 0.73$ & 0.00 & & Father: $0.84 \pm 0.81$ & 0.36 \\
& Child: $1.15 \pm 1.6$ & & & Child: $0.78 \pm 1.26$ & \\
2 & Mother: $1.66 \pm 0.85$ & 0.00 & & Father: $1.5 \pm 1.08$ & -0.02 \\
& Child: $2.44 \pm 1.80^{*}$ & & & Child: $1.63 \pm 1.70$ & \\
3 & Mother: $2.26 \pm 1.30$ & 0.07 & & Father: $2.08 \pm 1.50$ & 0.08 \\
& Child: $2.90 \pm 2.13^{* *}$ & & & Child: $1.91 \pm 2.04$ & \\
\hline
\end{tabular}

Results presented as mean $\pm S D$. ${ }^{*} t(41)=3.14, P<0.01$; **t(41) $=2.02, P \leq 0.05$

intensity ratings following venipuncture, girls reported significantly higher pain unpleasantness than boys. These authors suggested that while girls and boys may provide similar reports of pain intensity, girls may be more willing to report on the emotional dimension of pain than boys. Because a measure of pain emotional intensity was not included in the present study, this possibility could not be examined.

It was also expected that children whose mothers were present would report higher pain than children whose fathers were present; however, children's pain reports did not differ significantly depending on which parent was present. One possible explanation for the absence of parent sex difference on child pain ratings is that children in the present study provided their pain ratings by pointing to faces on a paper copy of the FPS, with their parents unable to see their ratings. Because children knew their pain ratings were not visible to their parents, they may have been less likely to vary their ratings based on their audience (ie, mothers or fathers). This explanation is supported by research based on social-cognitive learning theory showing that children cite expectations of negative interpersonal consequences following disclosure of feelings, including pain, as the primary reason for controlling their emotional expressions (19). If children in the present study felt confident that their parents could not see their pain ratings, they may not have altered their pain ratings based on their expectations of how their mother or father may react to their ratings. Therefore, even if children expected mothers to be more sympathetic to their experience of pain than fathers, the privacy of their pain ratings may have cancelled out the effect of these expectations.

Similar to the results from subjective child pain reports, sex differences were not discovered in either of the objective child pain measures included in the present study (heart rate and facial expression). The finding that child sex did not impact child heart rate was consistent with stated hypotheses, as well as previous research (6). We did not make a prediction about the effect of parent sex on child heart rate. To our knowledge, the present study is the first to examine whether child heart rate in response to pain differs depending on whether the mother or the father is present.

Contrary to our hypotheses, there were no significant differences between boys' and girls' facial expressions of pain. This result is somewhat unexpected, given that past research suggests that pain expression is more acceptable in females than males (9). Also in contrast to our hypotheses, we found that children whose mothers were present displayed similar facial expressions of pain to children whose fathers were present. This finding is also surprising because previous research suggests that mothers may respond more positively to their children's illness behaviour 
(such as behavioural displays of pain and discomfort) than fathers (20). Unlike children's subjective pain reports, which were given privately, children's facial expressions of pain were clearly visible to their parents. Nevertheless, children's facial expressions did not appear to be influenced by their audience. A possible explanation for the lack of sex differences in children's facial expressions of pain is that children in the present study did not experience enough pain to cause them to display very pronounced facial expressions. While children's average pain ratings ranged from 0 to 5.33, the overall mean pain rating was 1.84. It is possible that a floor effect may have contributed to the null results for sex differences in child facial expressions of pain. It is also possible that children were distracted by the process of providing frequent pain intensity ratings, leading to decreased pain expression and pain ratings.

In terms of parents' proxy ratings, it was originally hypothesized that mothers would give their children higher pain intensity ratings than fathers. However, this hypothesis was based on our prediction that children would display more pain in their facial expressions with mothers present than with fathers present. As discussed above, this was not the case. Analyses of parents' proxy ratings showed that there was a significant main effect of child sex and a significant interaction between child and parent sex. Follow-up analyses revealed that, on average, fathers gave their sons higher pain ratings than their daughters, while mothers' ratings of their sons' and daughters' pain intensity did not differ. The finding that fathers gave their sons higher pain ratings than their daughters (despite the fact that boys and girls had comparable facial expressions of pain) might indicate that fathers expect their sons to present a more stoic exterior during pain. In other words, fathers may expect their sons to display less pain than they are experiencing to conform to the stereotypically masculine ideal of withstanding and downplaying pain experiences. This may have led fathers in the present study to believe that the same facial expression of pain indicated more intense pain in their sons than it did in their daughters. A similar explanation was recently put forth by Sims et al (poster presented at the International Forum on Pediatric Pain, Halifax, Nova Scotia, October 2006) in a study of gender biases in pediatric pain ratings. In this study, adults watched video clips of an androgynous child undergoing an acute painful procedure. The child in the video clips was labelled as either a boy or a girl. Interestingly, participants provided higher pain intensity ratings when the child was labelled as a boy than when it was labelled as a girl. In the present study, this possible gender bias appeared to affect only fathers, perhaps indicating that fathers are more keenly attuned to gender-role stereotypes relating to pain expression than mothers.

In terms of parent-child agreement, our hypothesis that parents would underestimate their children's pain intensity levels was not supported for fathers. However, mothers tended to underestimate their children's pain in the latter phases of the cold pressor task. This finding is consistent with previous research showing maternal underestimation of child pain (2). The finding that father and child pain ratings did not differ significantly in any of the three phases of the cold pressor task indicates that it is inappropriate to assume that mothers' judgments of pain are representative of judgments made by both parents. It may also suggest that fathers are more accurate judges of their children's pain.

These findings must be interpreted with caution because kappa statistics revealed that parent-child agreement in the present study was generally poor for all parents. Parents may have had difficulty appreciating their children's pain due to the relatively low overall ratings provided by children, or by the novel situation of the cold pressor task itself. However, past studies have found that the cold pressor is a valid pain stimulus and that parents are capable of providing reasonably accurate proxy ratings of their children's pain during the cold pressor task (24). It is possible that the results of the present study, similar to those found by Chambers et al (2), demonstrate an inherent difficulty on the part of parents to accurately appraise their child's pain intensity. This would be in keeping with research showing that parents underestimate other internal conditions in their children such as depression and anxiety (31).

Although the present study provides interesting information regarding parent and child sex differences in children's pain ratings, several limitations should be noted. The experimental pain stimulus used in the present study provides an analogue to the pain that children experience in real life. Experimental pain studies allow for increased experimental control and precise definition of variables. However, additional research is needed to examine parent and child sex differences in clinical pain settings. In future research, it would also be desirable to focus more directly on parent-child verbal interactions. As examples, in the present study, it would have been interesting to examine whether boys and girls verbally expressed different amounts of pain in the presence of mothers versus fathers, and the impact of these verbalizations on children's self-reports and parents' proxy reports of child pain.

The fact that the present study examined simple sex differences (instead of gender differences) is a limitation. Gender includes not only biological differences, but behaviours and characteristics influenced by sociocultural factors such as masculinity and femininity (14). Future research should take both sex and gender into account when examining how families interact when children experience pain. Children in the present study completed the pain task in the presence of either their mother or their father (ie, only one parent was present per child). Future research involving children and both of their parents may allow for a more direct comparison between mothers and fathers. It should also be noted that the children included in the present study were those who displayed relatively good tolerance for cold pressor pain. Thirty-seven children out of a total sample of 110 were excluded from the analyses because they chose to discontinue the cold pressor task early. Although the number of excluded boys and girls was equal, it is possible that these children may have differed systematically, on variables other than sex (eg, anxiety level), from the children who completed the cold pressor task.

The present study provides a first descriptive demonstration of the importance of considering both child and parent sex as determinants of how children react to painful events in the presence of a parent, and how parents rate their children's pain. The social ecological model used here suggests that future research in this area should explore additional individual child and parent variables that have been shown to impact pain ratings, such as fear of pain, pain catastrophizing and previous pain experiences $(8,32-35)$.

Parents are an important part of their children's lives and are often called on to help with varying aspects of pain assessment and treatment. The present study builds upon previous research in the area of pediatric pain by examining the role of both parent and child sex differences in children's pain experiences. The 
findings indicate that while children may respond to pain in a similar fashion in the presence of both parents, fathers may attribute more pain to their sons than daughters. This may suggest that fathers have different expectations for how their sons should display pain compared with their daughters. In addition, the results of this study indicate that mothers tend to underestimate their children's pain. Fathers do not appear to show this pattern and may actually provide more accurate ratings of their children's pain in an experimental setting. Further research including both fathers and mothers in clinical settings is required to extend these findings and begin to fill the gap in the literature that currently exists on the unique role that fathers play in their children's pain experiences.

\section{REFERENCES}

1. Perquin CW, Hazebroek-Kampschreur AA, Hunfeld JA, et al. Pain in children and adolescents: A common experience. Pain 2000;87:51-8

2. Chambers CT, Reid GJ, Craig KD, McGrath PJ, Finley GA. Agreement between child and parent reports of pain. Clin J Pain 1998;14:336-42.

3. Blount RL, Corbin SM, Sturges JW, Wolfe VV, Prater JM, James LD. The relationship between adults' behavior and child coping and distress during BMA/LP procedures: A sequential analysis. Behav Ther 1989;20:585-601.

4. Blount RL, Cohen LL, Frank NC, et al. The Child-Adult Medical Procedure Interaction Scale - Revised: An assessment of validity. J Pediatr Psychol 1997;22:73-88.

5. Blount RL, Sturges JW, Powers SW. Analysis of child and adult behavioral variations by phase of medical procedure. Behav Ther 1990;21:33-48

6. Chambers CT, Craig KD, Bennett SM. The impact of maternal behavior on children's pain experiences: An experimental analysis. J Pediatr Psychol 2002;27:293-301.

7. Goodman JE, McGrath PJ. Mothers' modeling influences children's pain during a cold pressor task. Pain 2003;104:559-65.

8. Craig KD, Pillai Ridell RR. Social influences, culture, and ethnicity. In: McGrath PJ, Finley GA, eds. Pediatric Pain: Biological and Social Context. Seattle: IASP Press, 2003:159-82.

9. Unruh A, Campbell MA. Gender variation in children's pain experiences. In: McGrath PJ, Finley A, eds. Chronic and Recurrent Pain in Children and Adolescents. Seattle: IASP Press, 1999:199-241.

10. Phares V, Lopez E, Fields S, Kamboukos D, Duhig AM. Are fathers involved in pediatric psychology research and treatment? J Pediatr Psychol 2005;30:631-43.

11. Phares V. Where's poppa? The relative lack of attention to the role of fathers in child and adolescent psychopathology. Am Psychol 1992;47:656-64.

12. Cassano M, Adrian M, Veits G, Zeman J. The inclusion of fathers in the empirical investigation of child psychopathology: An update. J Clin Child Adolesc Psychol 2006;35:583-9.

13. Seagull EA. Beyond mothers and children: Finding the family in pediatric psychology. J Pediatr Psychol 2000;25:161-9.

14. Myers CD, Riley JL III, Robinson ME. Psychosocial contributions to sex-correlated differences in pain. Clin J Pain 2003;19:225-32.

15. Fillingim RB. Sex-related influences on pain: A review of mechanisms and clinical implications. Rehabil Psychol 2003;48:165-74.

16. Goodenough B, Thomas W, Champion GD, et al. Unravelling age effects and sex differences in needle pain: Ratings of sensory intensity and unpleasantness of venipuncture pain by children and their parents. Pain 1999;80:179-90

17. Goodenough B, Kampel L, Champion GD, et al. An investigation of the placebo effect and age-related factors in the report of needle pain from venipuncture in children. Pain 1997;72:383-91.

18. Zeltzer LK, Fanurik D, LeBaron S. The cold pressor pain paradigm in children: Feasibility of an intervention model (Part II). Pain 1989;37:305-13.
ACKNOWLEDGEMENTS: The authors thank the participants and staff of Science World for their cooperation with this project. We thank Melanie Badali, Andrea Cszizar, Tara Martin, Rebecca Pillai Riddell and Christy Stoochnoff for their assistance with data collection and coding.

SUPPORT: EC Moon is supported by a doctoral award from the Social Sciences and Humanities Research Council of Canada (SSHRC). CT Chambers and PJ McGrath are supported by Canada Research Chairs. KD Craig is supported by a Senior Investigator career award from the Canadian Institutes of Health Research (CIHR). This research was supported by operating grants from SSHRC to KD Craig and CIHR to CT Chambers.

19. Zeman J, Garber J. Display rules for anger, sadness, and pain: It depends on who is watching. Child Dev 1996;67:957-73.

20. Walker LS, Zeman JL. Parental response to child illness behavior. JPediatr Psychol 1992;17:49-71.

21. Schechter NL, Bernstein BA, Beck A, Hart L, Scherzer L. Individual differences in children's response to pain: Role of temperament and parental characteristics. Pediatrics 1991;87:171-7.

22. Zeman J, Shipman K. Children's expression of negative affect: Reasons and methods. Dev Psychol 1996;32:842-9.

23. Miller DC. Handbook of research design and social measurement: A text and reference book for the social and behavioral sciences, 4th edn. New York: Longman; 1983.

24. von Baeyer CL, Piira T, Chambers CT, Trapanotto M, Zeltzer LK. Guidelines for the cold pressor task as an experimental pain stimulus for use with children. J Pain 2005;6:218-27.

25. Bieri D, Reeve RA, Champion GD, Addicoat L, Ziegler JB. The Faces Pain Scale for the self-assessment of the severity of pain experienced by children: Development, initial validation, and preliminary investigation for ratio scale properties. Pain 1990;41:139-50.

26. Chambers CT, Giesbrecht K, Craig KD, Bennett SM, Huntsman E. A comparison of faces scales for the measurement of pediatric pain: Children's and parents' ratings. Pain 1999;83:25-35

27. Prkachin KM. The consistency of facial expressions of pain: A comparison across modalities. Pain 1992;51:297-306.

28. Gilbert CA, Lilley CM, Craig KD, et al. Postoperative pain expression in preschool children: Validation of the child facial coding system. Clin J Pain 1999;15:192-200.

29. Fleiss, JL. Statistical methods for rates and proportions, 2nd edn. New York: Wiley, 1981.

30. Tsao JC, Glover DA, Bursch B, Ifekwunigwe M, Zeltzer LK. Laboratory pain reactivity and gender: Relationship to school nurse visits and school absences. J Dev Behav Pediatr 2002;23:217-24.

31. Kashani JH, Orvaschel H, Burk JP, Reid JC. Informant variance: The issue of parent-child disagreement. J Am Acad Child Psychiatry 1985;24:437-41.

32. Vervoort T, Goubert L, Eccleston C, Bijttebier P, Crombez G. Catastrophic thinking about pain is independently associated with pain severity, disability, and somatic complaints in school children and children with chronic pain. J Pediatr Psychol 2006;31:674-83.

33. Goubert L, Eccleston C, Vervoort T, Jordan A, Crombez G. Parental catastrophizing about their child's pain. The paren version of the Pain Catastrophizing Scale (PCS-P): A preliminary validation. Pain 2006;123:254-63.

34. Asmundson GJG, Vlaeyen JWS, Crombez G, eds. Understanding and treating fear of pain. Oxford: Oxford University Press, 2004

35. Pate JT, Blount RL, Cohen LL, Smith AJ. Childhood medical experience and temperament as predictors of adult functioning in medical situations. Child Health Care 1996;25:281-98. 


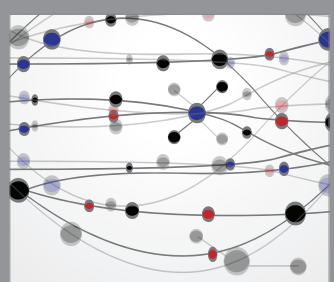

The Scientific World Journal
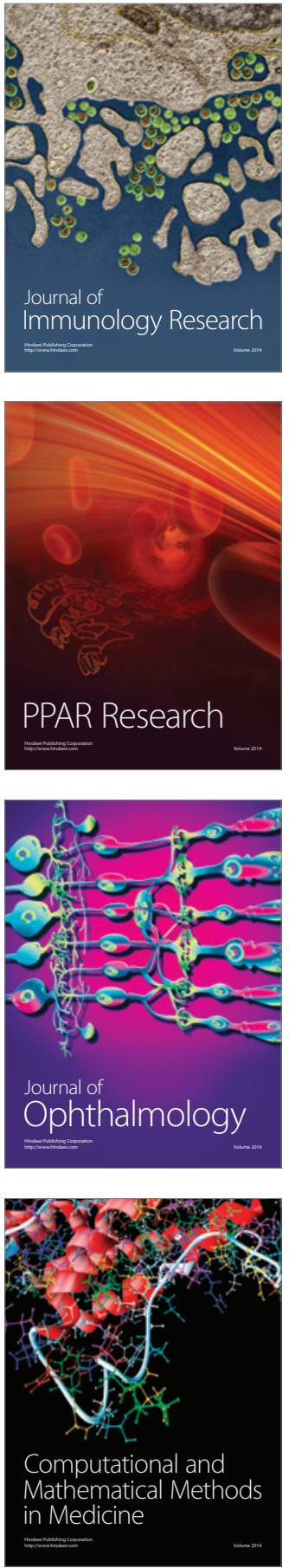

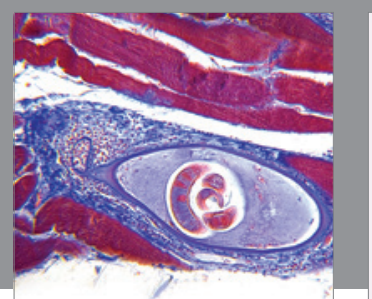

Gastroenterology Research and Practice

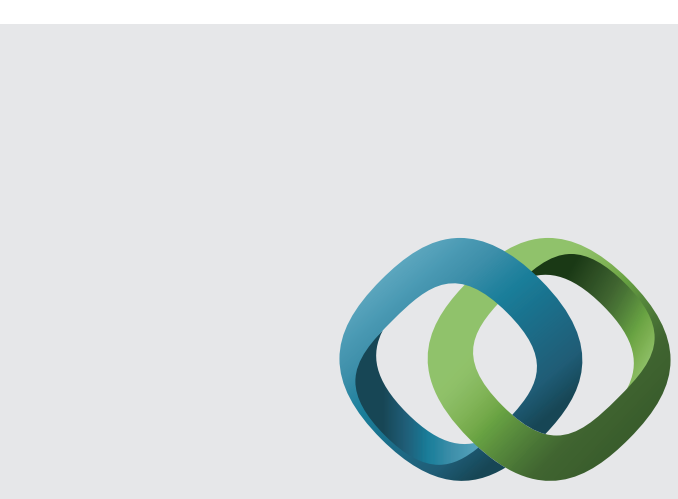

\section{Hindawi}

Submit your manuscripts at

http://www.hindawi.com
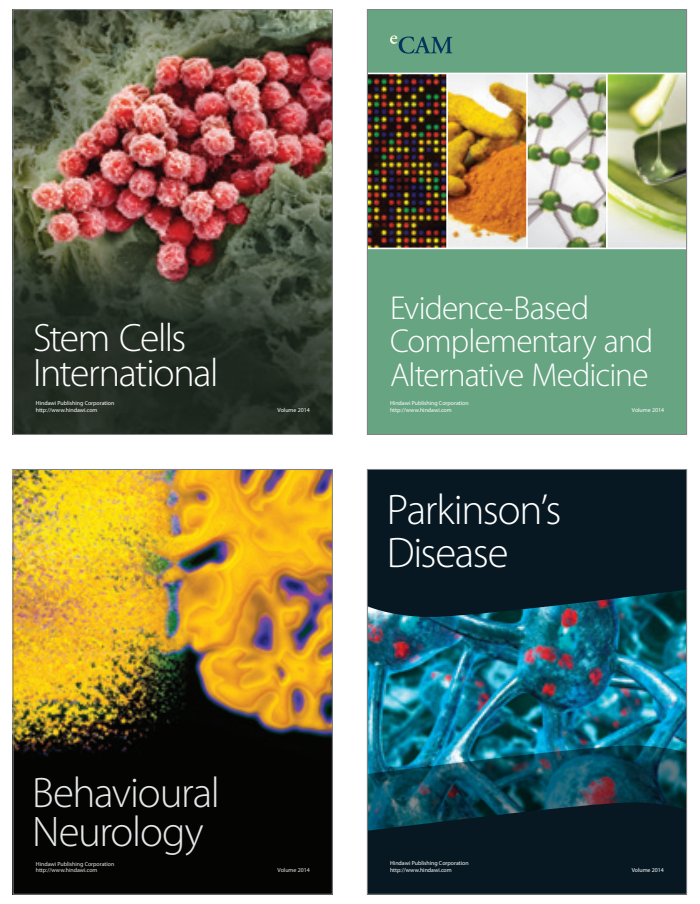
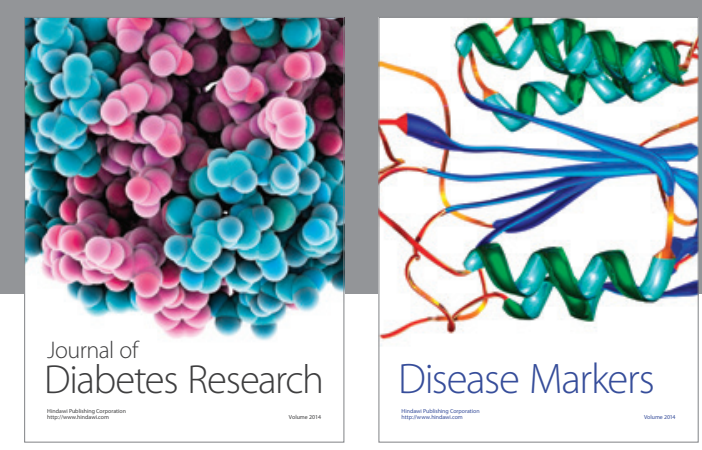

Disease Markers
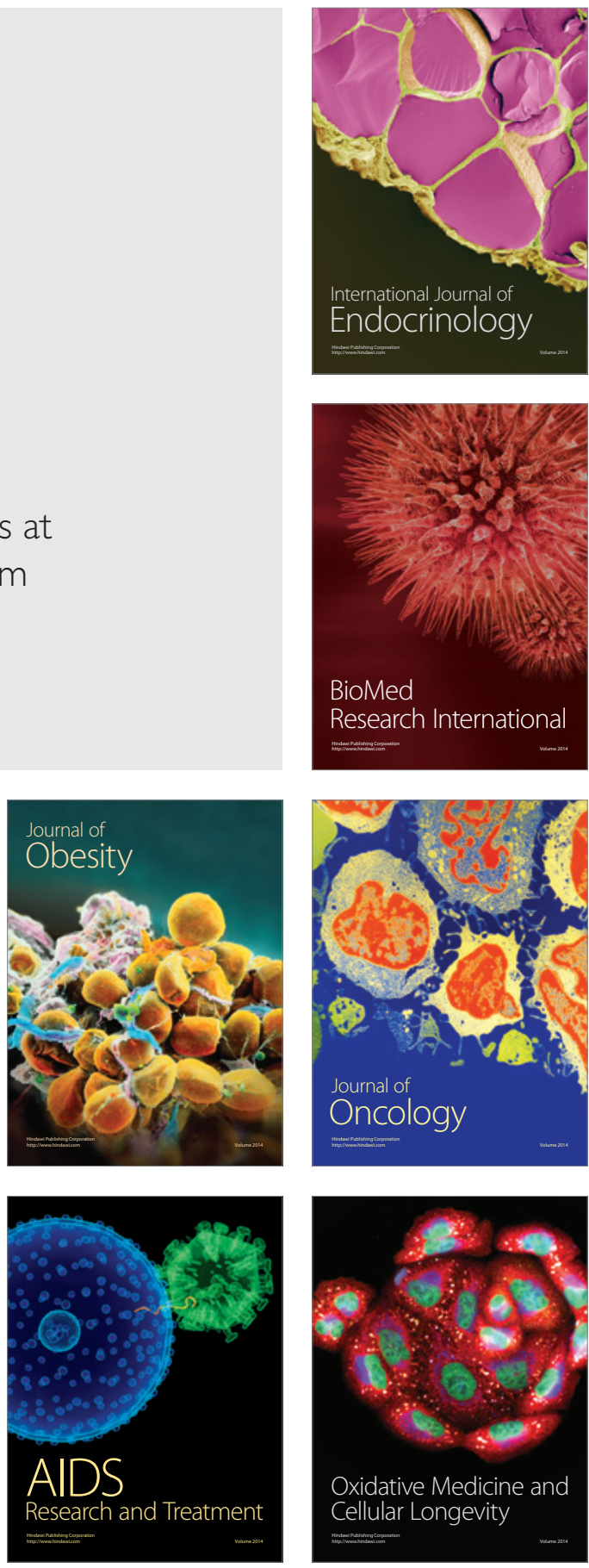